\section{Marginal vein is not a varicose vein; it is a venous malformation}

\author{
Byung-Boong Lee \\ Center for the Lymphedema and Vascular \\ Malformations, George Washington \\ University, Washington DC; Uniformed \\ Services University of the Health \\ Sciences, Bethesda, MD, USA
}

\section{Abstract}

Marginal vein (MV) is one form of venous malformation (VM); MV is not a varicose vein. MV is the outcome of defective development during the later stage of embryogenesis while the vein trunk is formed. It is an embryonic vein tissue remnant remaining on birth following the failure of normal involutional process. MV is the most common VM involved to Klippel-Trenaunay syndrome (KTS); together with the lymphatic malformation, MV is one of two clinically most important congenital vascular malformation components among KTS. MV causes chronic venous insufficiency (CVI) due to a unique condition of avalvulosis (lack of venous valve development) it accompanies with. Besides, it accompanies a high risk of venous thromboembolism (VTE) due to its structural defect with a lack of smooth muscle cell to form the media properly as a truncular VM infrequently causing fatal pulmonary embolism. Therefore, the MV is indicated for the surgical excision whenever feasible not only for the prevention of VTE and CVI but also for abnormal long bone growth known as vascular bone syndrome as well as lymphatic complication precipitated by MV.

\section{Introduction}

Marginal vein (MV) ${ }^{1-4}$ is often mistakenly considered as a varicose vein since most of MV locates very superficially beneath the skin with a minimum soft tissue coverage although it runs on the lateral aspect of the lower extremity, which is odd/unusual location for common varicose veins. $\mathrm{MV}$ is not a matured vein like varicose veins (of superficial vein system); vein; it is an embryonic vein remnant following the failure of normal involutional process through the maturation period of vein trunk formation and remains after the birth. Although MV looks like ordinary varicose vein of saphenous/superficial vein especially when it is located in superficially, MV is a lot more clinically serious not only to cause severe chronic venous insufficiency (CVI) but also constant source of intravascular coagulation resulting in venous thrombo-embolism (VTE) (Figure 1). MV is one of venous malformations (VMs);-8 VM is a common form of congenital vascular malformations (CVMs) ${ }^{9-12}$ and the MV is one form of truncular VMs as the outcome of defective development during the later stage of embryogenesis while the vascular/venous trunk is formed. The extent and severity of the $\mathrm{MV}$ are variable depending upon the degree of defective development along the last/truncular stage of embryogenesis while forming the vein trunk so that all the MVs present in different lengths as well as different locations; they are also named differently from lateral embryonic vein to sciatic vein. ${ }^{3,13-15}$ However, all these laterally located embryonic veins have same defective condition of the vein wall with insufficient smooth muscle layers development (cf. varicose vein). Besides, as a part of defective development of the venous wall, they accompany a unique condition of the lack of normal venous valves development known as avalvulosis. The MV has a unique clinical significance as the most common form of VM involved to Klippel-Trenaunay syndrome (KTS). ${ }^{16-19}$ KTS is a well known name-based eponym representing a clinical condition of various congenital anomalies affecting not only the vascular system but also the soft tissue as well as the skeletal system. The MV/lateral embryonic vein as a truncular VM lesion ${ }^{14,20,21}$ is potentially most dangerous CVM lesion among various vascular malformation components involved to the KTS; together with less common extratruncular VM, MV as a truncular VM belongs to the CVM components of KTS.

Together with this VM group, ${ }^{22-25}$ the lymphatic malformation (LM) group ${ }^{26-29}$ affects the clinical condition of the KTS as second most serious CVM components, directly and indirectly in various degrees together with capillary malformation (CM);30,31 LM presents in the majority as a truncular lesion known as primary lymphedema and/or extratruncular lesion known as lymphangioma among KTS. These two, VM and LM, combined form of CVMs are classified as hemolymphatic malformation (HLM) by modified Hamburg Classification in view of inseparable impact on overall hemodynamic status ${ }^{32-35}$ (Tables 1 and 2). Nevertheless, such complicated condition of the MV, often combined with other CVMs (e.g. deep vein aplasia/hypoplasia) has been often neglected as a relatively benign condition although the chronic venous hypertension generated by the unique condition of avalvulosis - lack of venous valve - will give a profound impact on the CVI.

Lately, MV was found to generate much more serious condition to cause the VTE. When this MV is combined with a unique condition of coagulopathy, which is common
Correspondence: Byung-Boong (B.B.) Lee, Center for Vein, Lymphatics and Vascular Malformation, George Washington University School of Medicine, Washington, DC, USA.

Division of Vascular Surgery, Department of Surgery, George Washington University Medical Center, 22nd and I Street, NW, 6th Floor, Washington, DC 20037 USA.

E-mail: bblee38@comcast.net

Key words: marginal vein, venous malformation, lymphatic malformation, Klippel-Trenaunay syndrome, venous thromboembolism, vascular bone syndrome.

Received for publication: 12 May 2014.

Revision received: 4 July 2014.

Accepted for publication: 7 July 2014.

This work is licensed under a Creative Commons Attribution 3.0 License (by-nc 3.0).

(c) Copyright B.-B. Lee, 2014

Licensee PAGEPress, Italy

Veins and Lymphatics 2014; 3:4050

doi:10.4081/vl.2014.4050

among the extratruncular VM lesions, it infrequently becomes a source of serious, even fatal, pulmonary embolism (PE) as well. ${ }^{36-39}$

Therefore, proper understanding on the MV is warranted for all the phlebologists who will have more chance to encounter such unique condition mimicking innocuous varicose veins than other clinical specialists.

\section{Definition}

The MV is one of the VMs, and VM is one of the CVMs affecting the venous system alone. ${ }^{9-12}$

CVM represents a whole group of birth defects caused by the developmental arrest during the embryogenesis to form the vascular system: artery, vein, and lymphatics. Depending upon the embryological stage when the defective development occurs, its clinical behavior is affected profoundly by unique embryological characteristics originated from the mesenchymal cells/angioblasts. ${ }^{40-43}$

Therefore, all these inborn vascular defects exist already at birth and the embryonic tissue remnant originated from the defective development in its early stage continues to grow at a rate that is proportional to the growth rate of the body (cf. hemangioma); this unique group originated from the early stage is further defined/sub-classified to the extratruncular type to differentiate from truncular type which represents other group of defective development originated from the late stage. The extratruncular lesions remain as a cluster of malformed vessels since defective development 
Table 1. Hamburg Classification of congenital vascular malformations.

Malformations types according to Hamburg Classification*

Predominantly arterial defects

Predominantly venous defects

Predominantly arteriovenous shunting defects

Predominantly lymphatic defects

\section{Combined vascular defects}

*Based on the consensus on congenital vascular malformation through the international workshop in Hamburg, Germany, 1988, and subsequently modified. Capillary malformation was not included.

occurred while the vascular structure is still in primitive reticular network.

This CVM group is classified together with the vascular tumor group under the category of the vascular anomaly; the most of vascular tumor is represented by (neonatal or infantile) hemangioma. ${ }^{44-47}$ CVM and vascular tumor/ hemangioma represent entire anomalous vascular structures together but both groups are totally different not only its etio-pathogenesis but also its clinical behavior. ${ }^{48}$

The Hamburg Classification ${ }^{32-35}$ has a unique value to provide not only different embryological characteristics of the CVMs from different embryonic stages but also its anatomical, histological, patho-physiological, and hemodynamic status for accurate diagnosis to improve its clinical management. The Hamburg Classification defined the CVMs to six groups based on the vascular systems involved: arterial, ${ }^{49,50}$ venous ${ }^{51-54}$ arteriovenous (AVM), ${ }^{55-58} \mathrm{LM}^{59-62}$ capillary, ${ }^{30,31}$ and combined vascular malformations. ${ }^{63-65}$ When $\mathrm{LM}^{66-68}$ is mixed/co-exists with VM or $\mathrm{AVM}^{69-71}$ as a combined form of the CVM, they were named to HLM ${ }^{21,65,72}$ (Table 1).

Based on Hamburg Classification, each CVM is further sub-classified to two different groups in order to verify unique embryological characteristics certain CVM groups possess: Extratruncular and Truncular lesions based on the embryological stage when developmental arrest has occurred ${ }^{32-35}$ (Table 2).

The extratruncular lesions represent the defective development occurred in the earlier stage of embryonic life retaining the mesenchymal cells (angioblasts) characteristics of mesodermal origin. Therefore, they possess evolutional potential to grow when stimulated internally (e.g. menarche, pregnancy, and hormone) or externally (e.g. trauma, surgery)..$^{40-43}$

On contrary, the truncular lesions no longer possess this embryonic characteristics of the mesenchymal cells since they represent the defective development during the later stage of the embryonic development during the vascular trunk formation period. ${ }^{40-43}$ However, truncular lesions cause more serious hemodynamic consequences related to the type of CVM (e.g. marginal veins) despite minimal risk of recurrence
Table 2. Hamburg Classification of congenital vascular malformations: forms and embryological subtypes.

\section{Extratruncular forms*}

Infiltrating, diffuse

Limited, localized

Truncular forms*

Aplasia or obstruction

Hypoplasia; aplasia; hyperplasia

Stenosis; membrane; congenital spur

\section{Dilatation}

Localized (aneurysm)

Diffuse (ectasia)

*Congenital vascular malformation represents developmental arrest at the different stages of embryonic life: Earlier stage Extratruncular form; Later stage - Truncular form. Both forms may exist together; may be combined with other various malformations (e.g. capillary, arterial, arteriovenous shunting, venous, hemolymphatic and/or lymphatic); and/or may exist with hemangioma.

Therefore, an extreme variety of the clinical behavior of the CVM lesions is heavily influenced by unique embryological characteristics of different stages of embryogenesis. Accordingly, CVM lesions are known as an enigma of modern medicine with a wide range of clinical presentations, unpredictable clinical course, and erratic response to treatment with the potential for high rates of recurrence. ${ }^{73-76}$

Extratruncular VM lesions never involve the main trunk of formed vein itself but remain as an independent lesion from the named/matured vein since they are pre-truncal embryonic lesions occurred before the main vascular trunks are formed. Therefore, they represent clinically either as diffuse, infiltrating lesions or localized, limited lesions.

But the majority of truncular lesions are directly involved to the vein trunks since the defective development occurs along the late stage while the vascular trunk is formed as post-truncal fetal lesions. Therefore, they present as a deformed vein with various degrees of developmental defect (e.g. agenesis/rudimentary deep vein), often as incomplete or immature development (aplasia or hypoplasia) directly affecting the main axial veins.

Therefore, the truncular lesions no longer possess the evolutional potential with the risk of
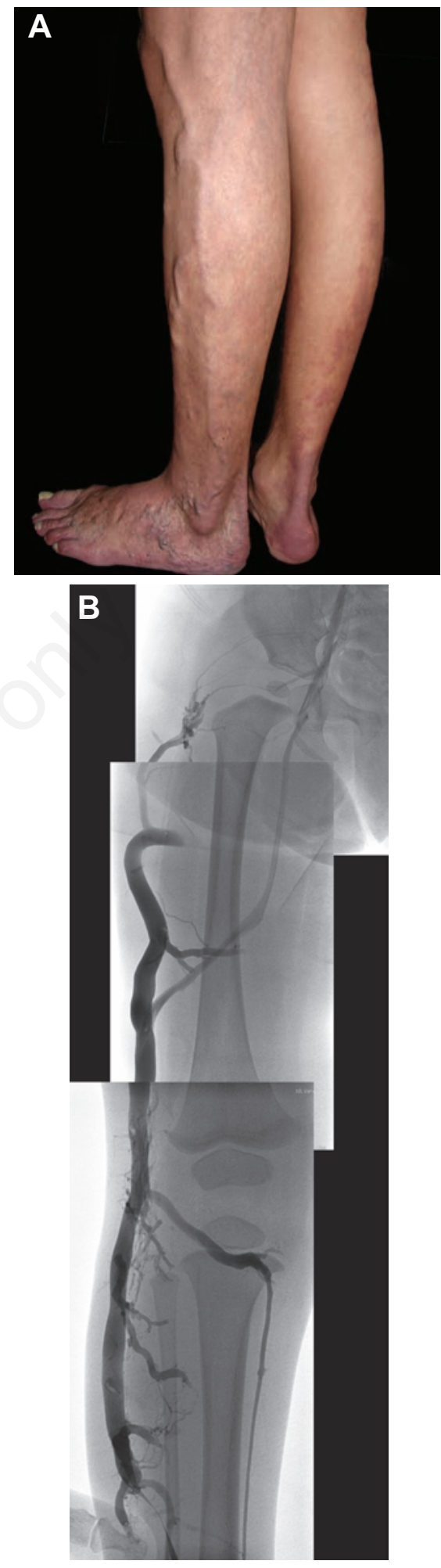

Figure 1. A) Clinical condition of the marginal/lateral embryonic vein along the lateral aspect of the left lower extremity. This unique vein structure is a persistent foetal remnant vessel following the failure of normal involution/regression; B) Angiographic finding of this marginal vein, which remains only major venous drainage route for this patient with a lack of normal development of deep venous system. Therefore, surgical excision to control the venous hypertension is contraindicated. From: Lee, 2012.3 
recurrence but have varying degrees of hemodynamic consequences due to defective vein trunk either as obstructive $\mathrm{e}^{77-80}$ or dilated ${ }^{81-84}$ lesion often affecting named vein trunk (e.g. femoral, popliteal, iliac veins).

In addition to such defective vessel condition presented either as an obstruction (e.g. vein web, spur, annulus, or septum $)^{85-88}$ or dilatation (e.g. popliteal or iliac vein ectasia/aneurysm $)^{89-92}$ to cause flow disturbance, another form of hypoplasia causes venous reflux with the absence of valves known as avalvulia/avalvulosis. This unique condition is a hallmark of the MV. Together with atresia of the lumen of venous trunks and venous aneurysms, avalvulosis is relatively common VM lesion.$^{93} \mathrm{MV}$ itself is a different form of truncular VM lesion as the outcome of defective maturation; it is an embryonic truncal vein remnant, which failed to undergo normal involutional process and persists/remains as the MV or the sciatic vein. ${ }^{1-4}$

Maturation and development of the main venous system in the primitive lower limb goes through three different stages: the first phase to form lateral peroneal/fibular vein draining into the cardinal vein; second phase to progress to form sciatic vein as a main vessel while medial draining vessel develop; and third/last phase to complete the evolutional process, in which the early lateral veins regresses. ${ }^{3,14}$ Failure of regression of the lateral peroneal vein will result in the existence of the MV at birth.

The MV occurs in varying extent and severity (e.g. limited sciatic vein), and they are grouped together as lateral embryonic vein. Extension of the MV therefore, may be variable depending upon the limb development stage involved; in mild case it is limited within calf level before it is connected/drained into the proximal deep venous system but its entirety might remain with an extension to the thigh and even to the buttock draining into internal iliac vein.

The MV persistence might have a close relationship with a failure of normal development of the deep venous system; more than one third of patients with the MV are known to have a defective deep venous system (e.g. hypoplasia of femoral vein, aplasia of iliac vein). In such case, MV remains as the main draining vein of the limb although it may exist together with normal deep veins. Therefore, precise evaluation of the deep venous system is mandated for the assessment of the MV.

But in general, MV has a numerous connection with the perforators, sometimes huge in caliber and fragile in consistence to make its management risky. Mild/micro AV fistula has been described in cases of extensive aplasia of deep veins. ${ }^{78,94,95}$

Valveless condition of MV as an embryonic vein causes a severe reflux resulting in chronic venous hypertension/stasis accompanying various degree of CVI. Besides, a defective ves- sel wall that is deficient in smooth muscle also carries a high risk of thrombo-embolic events and infrequently leads to fatal PE, especially among KTS patients. ${ }^{36-39}$

\section{Clinical assessment}

Correct assessment of MV together with the deep venous system is crucial for the treatment planning. Clinical examination is often easy to demonstrate the MV. However, collaterals or even the MV itself may not be easy to remain visible by increased subcutaneous fat or combined with extratruncular LM in which thickening of subcutis by lymphatic abnormal tissue may hide the vein.,93

But in general, the MV can be easily confirmed through the physical examination as an abnormal superficial draining vein of the lower limb which is sited on the lateral edge of the extremity frequently running beneath the coexisting CM known as a port wine stain. ${ }^{1-4}$ Unless it is located within thick subcutaneous fat along the swollen limb, the majority is quite visible as a protruding vein along the lateral aspect of the extremity invariably detected by a light palpation.

Laboratory evaluation for the diagnosis of the MV is sufficient only with non- to lessinvasive tests based on the Duplex ultrasonography (DUS), magnetic resonance imaging, and/or computerized tomography. DUS is the test of choice to assess the hemodynamic status of the MV and the deep vein system simultaneously (e.g. extent and severity of the reflux and outflow resistance). The deep vein system should be assessed both in lying and standing position to differentiate among normal, aplastic and hypoplastic venous segments.

DUS is also excellent for the mapping of the MV course to delineate entire length of MV, located supra- and sub-fascially, and site and size of perforators besides the extension of reflux..$^{8,22}$ Further evaluation with invasive tests (e.g. direct puncture phlebography together with ascending phlebography) can be deferred till needed as a road map for the surgical intervention ${ }^{8,22,93}$ (Figure 2).
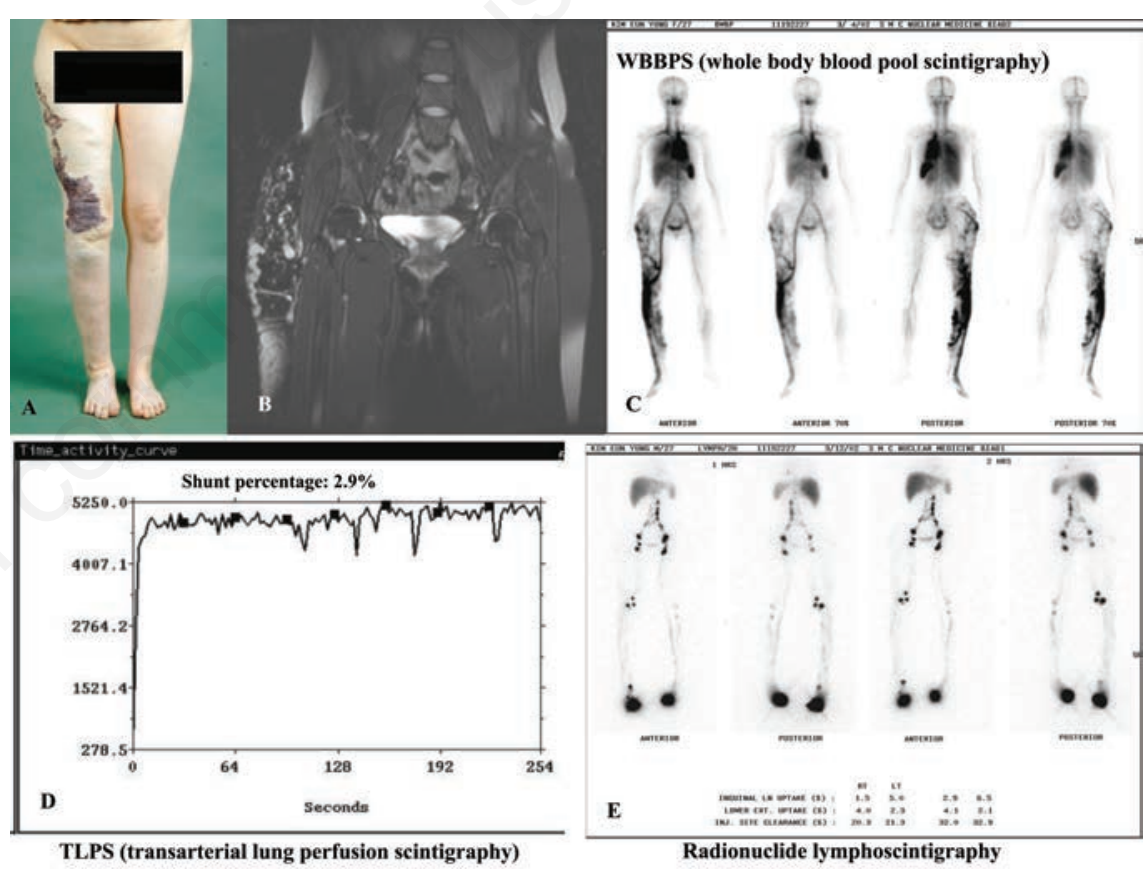

Figure 2. A) Clinical appearance of venous malformation (VM) lesion affecting the right lower extremity as a hemolymphatic malformation, mixed with lymphatic malformation and capillary malformation, often known as Klippel-Trenaunay syndrome. B) Magnetic resonance imaging finding of extratruncular VM lesion diffusely infiltrating in the soft tissue and muscles of right lower extremity. C) Whole body blood pool scintigraphy (WBBPS) findings of massive abnormal blood pool throughout entire right lower extremity; this WBBPS effectively ruled out any additional lesions throughout the body. D) Transarterial lung perfusion scintigraphy (TLPS) study that is negative for abnormal arteriovenous shunting - $2.9 \%$ is within normal range. E) Radionuclide lymphoscintigraphy findings of anatomically normal, but functionally abnormal double (deep and superficial) lymphatic transporting vessel, visualized along right lower extremity. This finding is consistent with a clinical finding of chronic lymphedema secondary to hypoplasia of the superficial lymphatic system, which is well compensated by deep system. From: Lee et al., 2007.. ${ }^{21}$ 
Arteriography seldom needed unless needed to rule out the AVM involved.

Proper technique should be known to perform the phlebography correctly in case of a large MV, because standard phlebography may show only the MV itself with poor demonstration of the deep venous system even if this is normal, bringing to a wrong conclusion of aplasia of deep veins. Therefore, phlebography should be combined with DUS, and phlebography alone should be avoided. ${ }^{1,96}$

A significant numbers of the MV accompany limb-length discrepancy either as an elongation or shortening of the affected limb. Hence, the assessment of the MV among KTS patients should be extended to possible involvement of angio-osteohypertrophy/hypotrophy known as vascular bone syndrome. ${ }^{97-100}$

Inconsistent terminology that characterizes the MV with the terms superficial, embryonic etc. has brought significant confusion. From the anatomical stand point the term superficial is a misnomer; although the MV remains in the superficial compartment of the lower extremity, it frequently penetrates the deep fascia and involves muscles of the deep compartment and remains with the high risk of potentially fatal thromboembolic events associated with the MV thrombosis like other major deep vein thrombosis (DVT).

From a therapeutic standpoint, evaluation for the MV deserves a special consideration on the hemodynamic alterations associated with blood stasis in these frequently valveless, truncal VM, carrying a high risk for thromboembolic events: DVT and PE.

\section{Management}

Anticoagulation is critical to the management of the MV due to its natural thrombosis prone condition; prophylactic anticoagulation with the weight adjusted low molecular weight heparin (LMWH) is generally recommended in all patients with the MV whenever possible. ${ }^{101-104}$ Especially when the MV is further combined with an aplastic or hypoplastic iliac-femoral venous system and the MV remains the major venous outflow of the lower extremity where the normal deep venous system is absent, the anticoagulation is essential. In this subgroup, thrombus within the vein would cause serious and often fatal PE. ${ }^{105-108}$

Nevertheless, MV is generally indicated for the removal whenever feasible to prevent if not control various acute as well as chronic complications: CVI, VTE, and vascular bone syndrome, as explained in previous section. But the feasibility of the surgical ablation of the MV will depend solely on the deep vein system status; only when the deep system is in normal condition, sudden increase of the venous influx following the removal of the MV can be tolerated by the deep system. If not tolerate, it would precipitate acute venous stasis and subsequent venous hypertension to cause acute venous gangrene.

The MV among the children in particular with evidence to cause a limb-length discrepancy should be removed as soon as possible in order to give a sufficient time for natural compensation to correct leg length discrepancy. ${ }^{13,109}$ In cases with normal deep veins, complete surgical resection of the MV either in a single stage or multiple stages remains the best and most ideal treatment to control the angio-0steodystrophy. ${ }^{97-100,110,111}$

When the deep vein system is in minimally hypoplastic condition, the MV can be removed in multistages to give a sufficient time for hypoplastic vein to be dilated spontaneously to tolerate new hemodynamic status following the resection of the MV to insure rerouting of venous flow. ${ }^{110,111}$ In cases of aplasia of the deep veins, the embryonal vein becomes a part of the main draining vessel of the limb and resection is no possible.

Therefore, surgical excision of the MV remains the treatment of choice in general and should be carried on to correct abnormal hemodynamic condition to cause various morbidities although endoluminal thermal ablation is occasionally technically feasible. Even for the patients with mildly hypoplastic deep veins it would be worthy for a trial as long as it would not compromise lower extremity blood return. In this subgroup of patients perioperative anticoagulation with LMWH should be considered.

The endovascular obliteration using the laser or radiofrequency is seldom technically applicable for the MV management due to extremely superficial location of the MV right beneath the skin, which makes sufficient tumescent anesthesia difficult. Therefore, currently available endovascular ablation by laser or radiofrequency is generally unsuitable for the MV under thin skin because of high risk of skin damage. .,8,22 $^{2}$

Foam sclerotherapy is also less effective and often difficult due to extremely large venous volume and relatively fast venous flow through the MV. Further, it is risky for DVT especially when large perforators are involved with potential extension of thrombosis to the deep vein system without barrier.

But the surgical excision is also often technically difficult due to extreme fragility of the defective vein with lack of media, huge and fragile perforators, and/or dense dysplastic lymphatic tissue surrounding the vein to dissect. Due to high risk of bleeding, the tourniquet is strongly recommended during the surgical procedure whenever applicable and closed stripping is often contraindicated. MV patients who are candidates for surgical removal, should receive perioperative anticoagulation with LMWH. ${ }^{112}$ Nevertheless, the results of surgical excision are good; recurrence has not been reported. ${ }^{113}$

\section{Conclusions}

Marginal vein is one of venous malformations due to defective development of venous trunk formation during the later stage of embryogenesis. MV is not an ordinary varicose vein but an embryonic vein with defective vessel structure; it therefore, accompanies high risk of venous thromboembolism in addition to chronic venous insufficiency caused by lack of venous valves (avalvulosis). As far as the deep vein system is normal, early ablation should be done whenever feasible especially when complicated with leg length discrepancy.

\section{References}

1. Mattassi R. Approach to marginal vein: current issue. Phlebology 2007;22:283-6.

2. Vollmar J, Voss E. Vena marginalis lateralis persistens - the forgotten vein of the angiologists. Vasa 1979;8:192-202.

3. Lee BB. Venous embryology: the key to understanding anomalous venous conditions. Phlebolymphology 2012;19:170-81.

4. Lee BB. Marginal vein is not a simple varicose vein: it is a silent killer! Review. Damar Cer Derg 2013;22:4-14:

5. Lee BB, Laredo J. Editorial. Venous malformation: treatment needs a bird's eye view. Phlebology 2013;28:62-3.

6. Lee BB, Laredo J. Chapter 63: Venous malformation and tumors: etiology, diagnosis, and managment. Part V. Congenital venous abnormalities. In: Bergan JJ, Bunke-Paquette N, eds. The vein book. 2nd ed. New York, NY: Oxford University Press; 2014. pp 541-548.

7. Lee BB, Baumgartner I. Contemporary diagnosis of venous malformation. J Vasc Diagnost 2013;1:25-34.

8. Lee BB, Baumgartner I, Berlien P, et al. Diagnosis and treatment of venous malformations consensus document of the International Union of Phlebology (IUP): updated 2013. Int Angiol 2014 Feb 25. [Epub ahead of print]

9. Lee BB, Bergan JJ. Advanced management of congenital vascular malformations: a multidisciplinary approach. J Cardiovasc Surg 2002;10:523-33.

10. Lee BB. Critical issues on the management of congenital vascular malformation. Ann Vasc Surg 2004;18:380-92.

11. Lee BB, Mattassi R, Loose D, et al. 
Consensus on controversial issues in contemporary diagnosis and management of congenital vascular malformation - Seoul Communication. Int J Angiol 2004;13:182-92.

12. Lee BB. Endovascular management of the congenital vascular malformation (CVM) is not a panacea. Damar Cer Derg 2013;22:1-3.

13. Weber J, Daffinger N. Congenital vascular malformations: the persistence of marginal and embryonal veins. Vasa 2006;36:67-77.

14. Lewis FT. Development of the veins in the limbs of rabbit embryos. Am J Anat 1906;5:113-20.

15. Hochstetter F. g.l.-Uilber die' Entwicklung der Extremitiitsvenen bei den Amnioten. Morph. Jahrb. 1891;7:1-43.

16. Klippel M, Trenaunay I. Du naevus variqueux et ostéohypertrophique. Arch Gén Méd 1900;3:641-72.

17. Servelle M. Klippel and Trénaunay's syndrome. Ann Surg 1985;201:365-73.

18. Gloviczki P, Stanson AW, Stickler GB, et al. Klippel-Trenaunay syndrome: the risks and benefits of vascular interventions. Surgery 1991;110:469-79.

19. Villavicencio JL. Congenital vascular malformations - predominantly venous? The syndrome of Klippel-Trenaunay. Scope Phlebol Lymphol 2000;71:116-25.

20. Kim YW, Lee BB, Cho JH, et al Haemodynamic and clinical assessment of lateral marginal vein excision in patients with a predominantly venous malformation of the lower extremity. Eur J Vasc Endovasc Surg 2007;33:122-7.

21. Lee BB, Laredo J, Lee TS, et al. Terminology and classification of congenital vascular malformations. Phlebology 2007;22:249-52.

22. Lee BB, Bergan J, Gloviczki P, et al. Diagnosis and treatment of venous malformations - consensus document of the International Union of Phlebology (IUP) 2009. Int Angiol 2009;28:434-51.

23. Lee BB. Not all venous malformations needed therapy because they are not arteriovenous malformations. Dermatol Surg 2010;36:347.

24. Lee BB. Venous malformation is not a hemangioma. Flebol Linfol Lect Vascul 2012;7:1021-3.

25. Lee BB, Laredo J. Hemangioma and venous/vascular malformation are different as an apple and orange! Acta Phlebol 2012;13:1-3.

26. Lee BB. Chapter 4: Lymphedema-diagnosis and treatment. In: Tredbar LL, Morgan CL, Lee BB, et al., eds. Lymphatic malformation. London: Springer-Verlag; 2008. pp $31-42$.

27. Lee BB, Kim YW, Seo JM, et al. Current concepts in lymphatic malformation (LM). Vasc Endovasc Surg 2005;39:67-81.

28. Lee BB. Lymphedema-angiodysplasia syndrome: a prodigal form of lymphatic malformation (LM). Phlebolymphology 2005; 47:324-32.

29. Lee BB, Andrade M, Antignani PL, et al. Diagnosis and treatment of primary lymphedema. Consensus document of the International Union of Phlebology (IUP) 2013. Int Angiol 2013;32:541-74

30. Berwald C, Salazard B, Bardot J, et al. Port wine stains or capillary malformations: surgical treatment. Ann Chir Plast Esthet 2006;51:369-72.

31. Goldman MP, Fitzpatrick RE, Ruiz-Esparza J. Treatment of port-wine stains (capillary malformation) with the flashlamppumped pulsed dye laser. J Pediatr 1993; 122:71-7.

32. Belov S. Anatomopathological classification of congenital vascular defects. Semin Vasc Surg 1993;6:219-24.

33. Belov S. Classification, terminology, and nosology of congenital vascular defects. In: Belov S, Loose DA, Weber J, eds. Vascular malformations. Reinbek: Einhorn-Presse; 1989. pp 25-30.

34. Rutherford RB. Classification of peripheral congenital vascular malformations. In: Ernst C, Stanley J, eds. Current therapy in vascular surgery. 3rd ed. St. Louis, M0: Mosby; 1995. pp 834-838.

35. Gloviczki P, Duncan AA, Kalra M, et al. Vascular malformations: an update. Perspect Vasc Surg Endovasc Ther 2009;21:133-48.

36. Aggarwal K, Jain VK, Gupta S, et al. Klippel-Trenaunay syndrome with a lifethreatening thromboembolic event. $\mathrm{J}$ Dermatol 2003;30:236-40.

37. Walder B, Kapelanski DP, Auger WR, Fedullo PF. Successful pulmonary thromboendarterectomy in a patient with Klippel-Trenaunay syndrome. Chest 2000;117:1520-2.

38. Ulrich S, Fischler M, Walder B, et al. Klippel-Trenaunay syndrome with small vessel pulmonary arterial hypertension. Thorax 2005;60:971-3.

39. Johnson JN, Driscoll DJ, Christopher GA, McGregor MB. Pulmonary thromboendarterectomy in Klippel-Trénaunay syndrome. J Thorac Cardiovasc Surg 2010;140:e41-3.

40. Leu HJ. Pathomorphology of vascular malformations: analysis of 310 cases. Int Angiol 1990;9:147-55.

41. DeTakats G. Vascular anomalies of the extremities. Surg Gynecol Obstet 1932;55:227-37.

42. Bastide G, Lefebvre D. Anatomy and organogenesis and vascular malformations. In: Belov S, Loose DA, Weber J, eds.
Vascular malformations. Reinbek: Einhorn-Presse Verlag; 1989. pp 20-22.

43. Woolard HH. The development of the principal arterial stems in the forelimb of the pig. Contrib Embryol 1922;14:139-54.

44. Mulliken JB, Glowacki J. Hemangiomas and vascular malformations in infants and children: a classification based on endothelial characteristics. Plast Reconstr Surg 1982;69:412-22.

45. Mulliken JB. Classification of vascular birthmarks. In: Mulliken JB, Young AE, eds. Vascular birthmarks: hemangiomas and malformations. Philadelphia, PA: WB Saunders; 1988. pp 24-37.

46. Mulliken JB, Zetter BR, Folkman J. In vivo characteristics of endothelium from hemangiomas and vascular malformations. Surgery 1982;92:348-53.

47. Mulliken JB. Cutaneous vascular anomalies. Semin Vasc Surg 1993;6:204-18.

48. Lee BB. Venous malformation and haemangioma: differential diagnosis, diagnosis, natural history and consequences. Phlebology 2013;28:176-87.

49. Agrawal A, Whitehouse R, Johnson RW, Augustine T. Giant splenic artery aneurysm associated with arteriovenous malformation. J Vasc Surg 2006;44:1345-9.

50. Miele VJ, Rosen CL, Carpenter J, et al. Vertebral artery-to-middle cerebral artery bypass with coil embolization of giant internal carotid artery aneurysm: technical case report. Neurosurgery 2005;56:E1159; discussion.

51. Lee BB, Do YS, Byun HS, et al. Advanced management of venous malformation (VM) with ethanol sclerotherapy: midterm results. J Vasc Surg 2003;37:533-8.

52. Lee BB. Current concept of venous malformation (VM). Phlebolymphology 2003;43:197-203.

53. Lee BB, Kim DI, Huh S, et al. New experiences with absolute ethanol sclerotherapy in the management of a complex form of congenital venous malformation. J Vasc Surg 2001;33:764-72.

54. Lee BB. Les malformations veineuses congénitales: évolution des concepts actuels de diagnostic et de traitement. Angéiologie 1998;50:17-9.

55. Lee BB, Baumgartner I, Berlien HP, et al. Consensus document of the International Union of Angiology (IUA) - 2013. Current concept on the management of arteriovenous management. Int Angiol 2013; 32:9-36.

56. Lee BB. Chapter 76: Mastery of vascular and endovascular surgery. In: Zelenock GB, Huber TS, Messina LM, et al., eds. Arteriovenous malformation. Philadelphia, PA: Lippincott, Williams and Wilkins; 2006. pp 597-607.

57. Lee BB, Lardeo J, Neville R. Arterio- 
venous malformation: how much do we know? Phlebology 2009;24:193-200.

58. Lee BB, Laredo J, Deaton DH, Neville RF. Chapter 53: Arteriovenous malformations: evaluation and treatment. In: Gloviczki P, ed. Handbook of venous disorders: guidelines of the American Venous Forum. 3rd ed. London: A Hodder Arnold: 2009. pp 583-593.

59. Lee BB, Laredo J, Seo JM, Neville R. Chapter 29: Treatment of lymphatic malformations. In: Mattassi R, Loose DA, Vaghi M, eds. Hemangiomas and vascular malformations. Milan: Springer-Verlag; 2009. pp 231-250.

60. Lee BB, Villavicencio JL. Primary lymphedema and lymphatic malformation: are they the two sides of the same coin? Eur J Vasc Endovasc Surg 2010;39:646-53.

61. Lee BB, Andrade M, Bergan J, et al. Diagnosis and treatment of primary lymphedema - consensus document of the International Union of Phlebology (IUP) 2009. Int Angiol 2010;29:454-70.

62. Lee BB, Laredo J, Neville R. Chapter 51: Primary lymphedema as a truncular lymphatic malformation. Section XI Lymphedema and congenital vascular malformation. In: Lee BB, Bergan J, Rockson SG, eds. Lymphedema: a concise compendium of theory and practice. 1st ed. London: Springer-Verlag; 2011. pp 419-426.

63. Noel AA, Gloviczki P, Cherry KJ Jr, Rooke TW, Stanson AW, Driscoll DJ. Surgical treatment of venous malformations in Klippel-Trenaunay syndrome. J Vasc Surg 2000;32:840-7.

64. Gloviczki P, Hollier LH, Telander RL, et al. Surgical implications of KlippelTrenaunay syndrome. Ann Surg 1983;197:353-62.

65. Lee BB, Laredo J. Chapter 21: Classification: venous-lymphatic vascular malformation. Part 3. In: Allegra C, Antignani PL, Kalodiki E, eds. News in phlebology. Turin: Ed. Minerva Medica; 2013. pp 91-94.

66. Kim KH, Kim HH, Lee SK, et al. OK-432 intralesional therapy for lymphangioma in children. J. Korean Assoc Pediatr Surg 2001;7:142-6.

67. Park JH, Kim DI, Huh S, et al. Absolute ethanol sclerotherapy on cystic lymphangioma in neck and shoulder region. $J$ Korean Vasc Surg Soc 1998;14:300-3.

68. Lee BB, Kim DI, Whang JH, Lee KW. Contemporary management of chronic lymphedema - personal experiences. Lymphology 2002;35:450-5.

69. Lee BB, Laredo J, Kim YW, Neville R. Congenital vascular malformations: general treatment principles. Phlebology 2007;22:258-63.
70. Lee BB, Laredo J. Multidisciplinary approach in the management of a giant arteriovenous malformation in the right axillary region. J Vasc Surg 2008;48:775-6.

71. Jeon YH, Do YS, Shin SW, et al. Ethanol embolization of arteriovenous malformations: results and complications of 33 cases. J Kor Radiol Soc 2003;49:263-70.

72. Lee BB, Laredo J. Classification of congenital vascular malformations: the last challenge for congenital vascular malformations. Phlebology 2012;27:267-9.

73. Lee BB, Laredo J, Deaton D, Neville R. Chapter 82: Endovascular treatment of some congenital diseases - hemangioma and vascular malformation. Section XI, Textbook of peripheral vascular interventions. In: Heuser RR, Henry M, eds. Informa healthcare. 2nd ed. London: Informa Ltd.; 2008. pp 712-722.

74. Lee BB. Chapter 41: Congenital vascular malformation. In: Geroulakos G, van Urk $\mathrm{H}$, Hobson II RW, Calligaro KD, eds. Vascular surgery. 2nd ed.: cases, questions and commentaries. London: Springer-Verlag; 2006. pp 377-392.

75. Lee BB. Chapter 40: Congenital vascular malformation. In: Geroulakos G, van Urk $\mathrm{H}$, Hobson II RW, Calligaro KD, eds. Vascular surgery: cases, questions and commentaries. London: Springer-Verlag; 2003. pp 315-323.

76. Lee BB, Beaujean M. Nouvelles strategies dans la prise en charge des malformations vasculaires congenitales (MVC): un apercu de l'experience clinique Coreenne. Angeiologie 2004;56:11-25.

77. Eifert S, Villavicencio JL, Kao TC, et al. Prevalence of deep venous anomalies in congenital vascular malformations of venous predominance. J Vasc Surg 2000;31:462-71.

78. Belov S. Congenital agenesis of the deep veins of the lower extremity: surgical treatment. J Cardiovasc Surg 1972;13:594.

79. Raju S, Hollis K, Neglen P. Obstructive lesions of the inferior vena cava: clinical features and endovenous treatment. $\mathrm{J}$ Vasc Surg 2006;44:820.

80. Lee BB, Villavicencio L, Kim YW, et al. Primary Budd-Chiari syndrome: outcome of endovascular management for suprahepatic venous obstruction. J Vasc Surg 2006;43:101-10.

81. Gillespie DL, Villavicencio JL, Gallagher $\mathrm{C}$, et al. Presentation and management of venous aneurysms. J Vasc Surg 1997;26:845-52.

82. Sessa C, Nicolini P, Perrin M, et al. Management of symptomatic and asymptomatic popliteal venous aneurysms: a retrospective analysis of 25 patients and review of the literature. $\mathrm{J}$ Vasc Surg 2000;32:902-12.
83. Zamboni P, Cossu A, Carpanese L, et al. The so-called venous aneurysms. Phlebology 1990;5:45-50.

84. Friedman SG, Krishnasastry KV, Doscher W, Deckoff SL. Primary venous aneurysms. Surgery 1990;108:92-5.

85. Zamboni P, Pisano L, Mari C, et al. Membranous obstruction of the inferior vena cava and Budd-Chiari syndrome. Report of a case. J Cardiovasc Surg (Torino) 1996;37:583-7.

86. Nedelmann M, Kaps M, Mueller-Forell W. Venous obstruction and jugular valve insufficiency in idiopathic intracranial hypertension. J Neurol 2009;256:964-9.

87. Wang ZG, Jones RS. Budd-Chiari syndrome. In: Wang ZG, Jones RS, eds. Current problems in surgery. New York, NY: Mosby; 1996. pp 83-211.

88. Lee BB, Laredo J, Deaton D, Neville R. Chapter 83: Endovascular management of Budd-Chiari syndrome - suprahepatic inferior vena cava occlusive disease. Section XII, Textbook of peripheral vascular interventions. In: Heuser RR, Henry M, eds. Informa healthcare. 2nd ed. London: Informa Ltd.; 2008. pp 725-731.

89. Ilijevski NS, Radak S, Novakovic B, et al. Images in vascular medicine. Jugular vein aneurysm - ultrasonographic evaluation. Vasc Med 2006;11:51.

90. Fishman G, DeRowe A, Singhal V. Congenital internal and external jugular venous aneurysms in a child. Br J Plast Surg 2004;57:165-7.

91. Kersting S, Rössel T, Hinterseher I, et al. Isolated aneurysm of the internal jugular vein. Vasa 2008;37:371-3.

92. Bush S, Khan R, Stringer MD. Anterior jugular venous aneurysm. Eur J Pediatr Surg 1999;9:47-8.

93. Lee BB, Laredo J, Lee SJ, et al. Congenital vascular malformations: general diagnostic principles. Phlebology 2007;22:253-7.

94. Loose DA. Surgical management of venous malformations. Phlebology 2007; 22,6:276-82.

95. Mattassi R. Treatment of venous malformations. In: Mattassi R, Loose DA, Vaghi $\mathrm{M}$, eds. Hemangiomas and vascular malformations. Milan: Springer; 2003. pp 223-230.

96. Weber J. Invasive Diagnostik angeborene Gefaessfehler (Invasive diagnostic of CVM). In: Loose DA, Weber J, eds. Angeborene Gefäßmissbildungen. Luneburg: Verlag, Nordlanddruck; 1997. pp 127-63.

97. Belov S. Correction of lower limbs length discrepancy in congenital vascular-bone diseases by vascular surgery performed during childhood. Semin Vasc Surg 1993;6:245-51.

98. Dickinson P. Venous stasis and bone 
growth. Exp Med Surg 1953;11:49-53.

99. Mattassi R. Differential diagnosis in congenital vascular-bone syndromes. Semin Vasc Surg 1993;6:233-44.

100. Belov S. Hemodynamic pathogenesis of vascular-bone syndromes in congenital vascular defects. Int Angiol 1990;9:155-62.

101. Gouin-Thibault I, Arkam R, Nassiri S, et al. Markers of activated coagulation in patients with factor $\mathrm{V}$ Leiden and/or G20210A prothrombin gene mutation. Thromb Res 2002;107:7-11.

102. Cuderman TV, Bozic M, Peternel P, Stegnar M. Hemostasis activation in thrombophilic subjects with or without a history of venous thrombosis. Clin Appl Thromb Hemost 2008;14:55-62.

103. Enjolras 0, Ciabrini D, Mazoyer E, et al. Extensive pure venous malformations in the upper or lower limb: a review of 27 cases. J Am Acad Dermatol 1997;36:219-25.

104. Mason KP, Neufeld EJ, Karian VE, et al. Coagulation abnormalities in pediatric and adult patients after sclerotherapy or embolization of vascular anomalies. AJR Am J Roentgenol 2001;177:1359-63.

105. Poon MC, Kloiber R, Birdsell DC. Epsilonaminocaproic acid in the reversal of consumptive coagulopathy with platelet sequestration in vascular malformation of Klippel-Trenaunay syndrome. Am J Med 1989;87:211-3.

106. Aronoff DM, Roshon M. Severe hemorrhage complicating the KlippelTrenaunay-Weber syndrome. South Med J 1998;91:1073-5.

107. Katsaros D, Grundfest-Broniatowski S. Successful management of visceral Klippel-Trenaunay-Weber syndrome with the antifibrinolytic agent tranexamic acid (cyclocapron): a case report. Am Surg 1998;64:302-4 (C36).

108. Yamamoto H, Muneta T, Asahina S, Furuya K, Suzuki K. Lower leg fracture with Parkes-Weber syndrome complicated by disseminated intravascular coagulation. J Orthop Trauma 1995;9:449-52.

109. Belov S. Correction of lower limbs length discrepancy in congenital vascular bone disease by vascular surgery performed during childhood. Semin Vasc Surg 1993;6:245-51.

110. Loose, DA, Lorenz. A Die Chirurgie der Maginalvene (Surgery of the marginal vein). In: Loose DA, Weber J, eds. Angeborene Gefaessmissbildungen (Congenital vascular malformations). Lűneburg: Nordlanddruck; 1997. pp 230-244.

111. Mattassi R. Trattamento delle angiodisplasie di tipo venoso (treatment of venous vascular malformations). In: Mattassi R, Lose DA, Belov S, Vaghi M, eds. Malformazioni vascolari ed emangiomi. Milan: Springer; 2003. pp 116-123.

112. Noel A, Gloviczki P, Cherr K Jr, et al. Surgical treatment of venous malformations in Klippel-Trénaunay syndrome. J Vasc Surg 2000;32:840-7.

113. Kim YW, Do YS, Lee SH, Lee BB. Risk factors for leg length discrepancy in patients with congenital vascular malformation. J Vasc Surg 2006;44:545-53. 